\title{
REVIEW
}

\section{Use of Fingolimod in the Management of Relapsing- Remitting Multiple Sclerosis: Experience from Latin America}

Jorge Correale $\cdot$ Jose Flores $\cdot$ Juan Garcia Bonitto $\cdot$ Claudia Cárcamo Rodríguez •

Enedina M. L. Oliveira

To view enhanced content go to www.advancesintherapy.com

Received: May 22, 2015 / Published online: July 14, 2015

(c) The Author(s) 2015. This article is published with open access at Springerlink.com

\section{ABSTRACT}

Once-daily fingolimod $0.5 \mathrm{mg}$ (FTY720; Gilenya ${ }^{\circledR}$, Novartis Pharma AG, Basel, Switzerland) is a sphingosine 1-phosphate receptor modulator that is approved for the treatment of relapsing multiple sclerosis (MS); currently, this includes

Electronic supplementary material The online version of this article (doi:10.1007/s12325-015-0226-0) contains supplementary material, which is available to authorized users.

J. Correale $(\square)$

Department of Neurology, Institute for Neurological

Research Raúl Carrea, FLENI, Buenos Aires,

Argentina

e-mail: jcorreale@fleni.org.ar;

jorge.correale@gmail.com

J. Flores

Department of Neurology, National Institute of

Neurology and Neurosurgery, and Neurological

Center, ABC Hospital Santa Fe, Mexico City, Mexico

J. G. Bonitto

Servicio de Neurología, Clinica de Marly, and

Entidad Prestadora De Servicios de Salud Nogales,

Bogota, Colombia

C. C. Rodríguez

Department of Neurology, Pontificia Universidad

Católica de Chile, Santiago, Chile

E. M. L. Oliveira

Department of Neurology, Universidade Federal de

São Paulo, São Paulo, Brazil approval in 13 Latin American countries. However, despite a well-characterized efficacy and safety profile in a large clinical development program, thus far there has been limited representation of patients from across the Latin American region. Differences in MS disease characteristics have been reported for the Latin American population compared with Caucasians, which may be additional to recent improvements in MS diagnosis. Furthermore, healthcare provision and regional socioeconomic factors exist that are unique to Latin America compared with other regions. Therefore, to optimize MS treatment pathways and improve patient clinical outcomes, it is important to investigate the efficacy and safety profile of fingolimod using ethnically relevant data. Here, we review key data from Hispanic patients enrolled in the fingolimod clinical trial program, summarize recent findings from the FIRST LATAM study, and appraise fingolimod data from real-world patient populations.

Funding: Novartis Pharma AG, Basel, Switzerland.

Keywords: Efficacy; Fingolimod; Hispanic; Latin American; Neurology; Relapsingremitting multiple sclerosis; Safety 


\section{INTRODUCTION}

Fingolimod (FTY720; $\quad$ Gilenya $^{\circledR}$, Novartis Pharma AG, Basel, Switzerland) is a first-inclass, orally administered sphingosine-1 phosphate receptor (S1PR) modulator that is approved for the treatment of relapsing forms of multiple sclerosis (MS) [1]. It is currently approved in more than 80 countries globally, including the following 13 Latin American countries: Argentina, Brazil, Chile, Colombia, Costa Rica, Ecuador, El Salvador, Guatemala, Mexico, Panama, Peru, Uruguay, and Venezuela.

To date, more than 114,000 patients worldwide have been treated with fingolimod in clinical trial and post-marketing settings, with a total patient exposure of approximately 195,000 patient-years [2]; indeed, the efficacy of fingolimod has been well established. In pivotal, phase 3, controlled clinical trials, fingolimod demonstrated significant reductions in annualized relapse rates (ARRs), lesion-based magnetic resonance imaging (MRI) activity, and brain volume loss (BVL) compared with placebo and intramuscular (IM) interferon beta-1a (IFN $\beta-1 \mathrm{a}$; Table 1) [3-5], with beneficial effects sustained in long-term extension studies [6-10]. The most recent assessments of 'no evidence of disease activity' (NEDA), which incorporates relapses, new/newly enlarged T2 MRI lesions, disability progression, and BVL to form a four-component NEDA assessment of disease activity, identified that the likelihood of achieving NEDA-4 was more than fourfold greater with fingolimod than with placebo at 2 years [11], and was more than twofold greater with fingolimod than with IFN $\beta-1$ a at 1 year [12].

Furthermore, large real-world studies such as PANGAEA and MSBase have shown that patients with MS who switch from injectable therapies to fingolimod are significantly less likely to experience relapses or disability progression [13-15], and also demonstrate greater adherence to fingolimod than those who switch to other injectables [16, 17]. Evidence also suggests that fingolimod is a suitable therapy for patients switching from natalizumab due to JCV seroconversion, suboptimal response, or other tolerability reasons $[18,19]$.

As with most MS treatments to date, clinical trials of fingolimod have involved limited representation of patients from across Latin America. However, it is important to establish the efficacy and safety profile of fingolimod from ethnically relevant data to better inform the optimization of MS treatment pathways and thereby improve patient clinical outcomes, particularly in light of the increased treatment options for patients with relapsing-remitting MS (RRMS) in the Latin American region.

This is pertinent because, as more information on the prevalence and course of MS disease in patients across Latin America has become available, observations point to an increase in the frequency of MS across the region compared with a few decades ago [20]. The genetic characteristics of MS across Latin America are unique due to marked heterogeneous patient populations. A complex ethnic picture may directly impact both the genetic susceptibility to MS and the interpretation of pharmacogenomics data relating to MS drug therapies [21, 22]. This may also be confounded by MS-related environmental factors such as exposure to sunlight and incidence of childhood infections [23].

This review was conducted to summarize key trial data regarding the use of fingolimod for the treatment of MS across Latin America. Searches were conducted in PubMed (January 


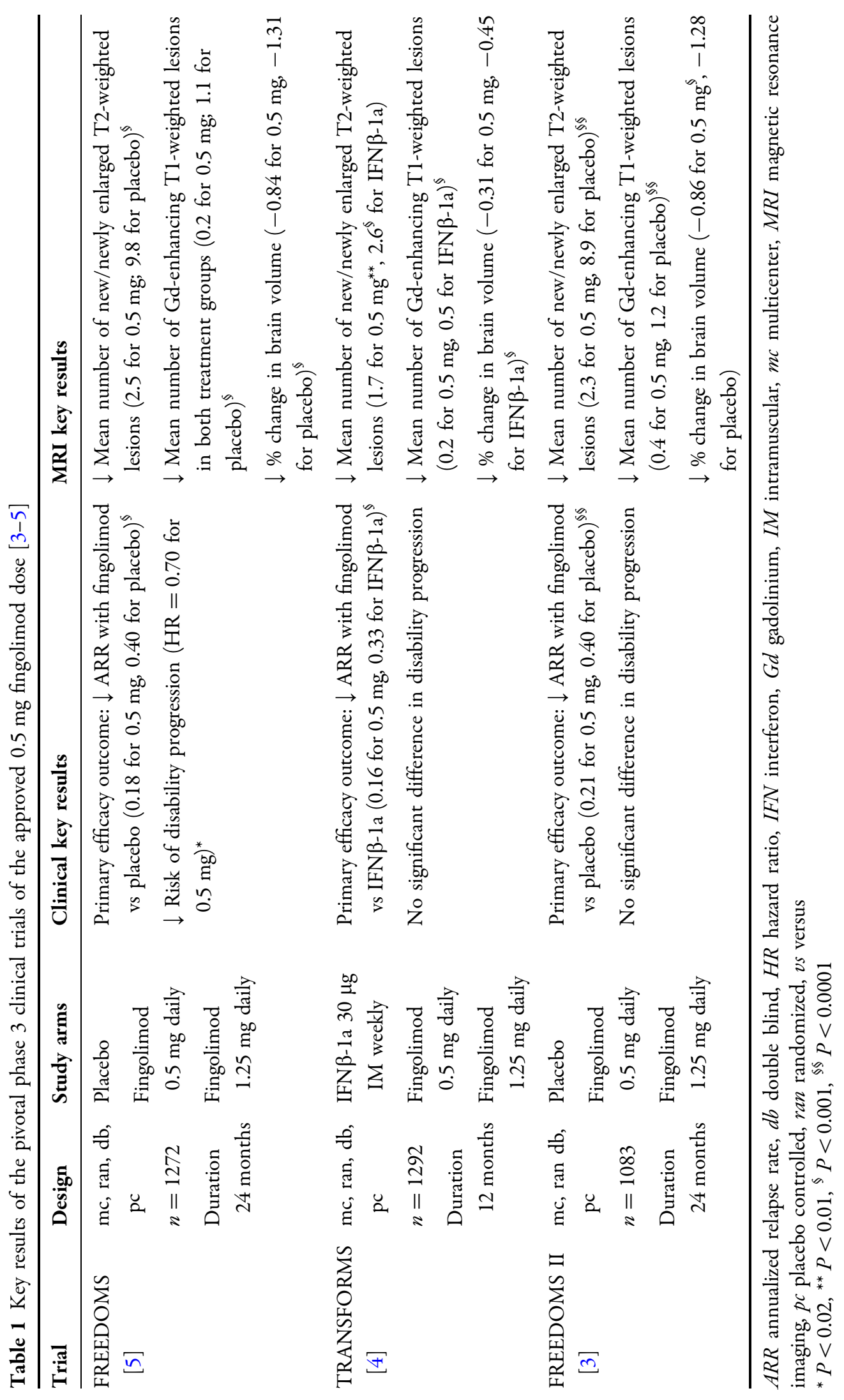


2015) using the terms fingolimod, Gilenya, FTY720, multiple sclerosis, Latin America, LATAM, South America, and Hispanic. Searching of congress abstracts was also conducted for the following meetings between 2012 and 2014: American Academy of Neurology (AAN), European Committee for Treatment and Research in Multiple Sclerosis (ECTRIMS), and Latin American Congress of Multiple Sclerosis (LACTRIMS). Findings from real-world patient populations and information relating to the practical use of fingolimod in clinics across Latin America were also provided by co-authors. In addition, we explore the recently published analyses of data from Hispanic patients enrolled in the fingolimod clinical trial program [24]. We also further describe recent findings from the FIRST LATAM study [25]. The analyses in this article are based on previously conducted studies and do not involve any new studies of human or animal subjects performed by any of the authors.

\section{FEATURES OF MS AND ITS MANAGEMENT IN LATIN AMERICA}

\section{MS in Latin America}

Worldwide, at least 2.3 million people have MS. The epidemiology of MS features various genetic and environmental factors, which underlie global prevalence variations [26]. The relative prevalence of MS in Latin American countries has historically been considered low when compared with North American and European countries [27]. In recent years, MS prevalence has increased in Latin America, as in the rest of the world, with suggestions that this is not just a result of improved diagnosis, although the reasons are presently not fully understood [20, 28]. Current estimates of prevalence in the region range from 0.8 to 21.5 cases per 100,000 inhabitants, with an incidence of 0.3-1.9 annual cases per 100,000 person-years [27].

In addition to increasing prevalence, differences exist between MS disease characteristics in Latin America and other regions of the world, particularly with regard to factors such as gender, age of onset, relative proportions of patients with relapsing versus progressive MS, and number of familial cases. A systematic review of the epidemiologic profile of MS in Argentina has suggested a less pronounced female:male bias in MS prevalence compared with other regions (1.5:1 vs. 2.6-3.2:1 in Sweden/Canada) [29-31]; however, these estimates can be variable, with Brazilian reports of the female:male MS prevalence of 4.1:1 [32]. A review of MS epidemiology in Argentina also reported the proportions of patients with relapsing-remitting (65.5\%), secondary progressive (21.5\%), primary progressive (10.6\%), and progressive relapsing MS (2.4\%) [29]—although the reported rates of RRMS in Latin America are again variable (ranging from 50\% in Ecuador [33] to 91\% in Brazil [32, 34]). Nevertheless, this differs from findings in Europe, for instance where relapsing/progressive proportions were identified as $77.4 \% / 22.6 \%$ [35]. It is plausible that these differences are the result of historically less-effective diagnosis, with fewer people diagnosed and treated early in the disease course in Latin America, leading to the identification of more progressive forms than in Europe. It is reasonable to speculate that this could change over time, with improved diagnosis and earlier initiation of more effective MS treatments across Latin America [36]. 
The immune profile of Latin Americans may also impact upon the course of MS. There is a reported relationship between childhood solar exposure and MS prevalence, possibly due to the immunomodulatory effects of vitamin $\mathrm{D}$ $[36,37]$; although the risk is not the same for everybody [38]. Furthermore, the immune response may also be affected by environmental factors such as parasitic infections [39]. The 'hygiene hypothesis' proposes that MS is less common in the developing world than in countries with lower levels of childhood infection. In support of this, a striking near-dichotomous relationship has been demonstrated between the prevalence of MS and that of Trichuris trichiura (a surrogate marker for other parasitic infections and low levels of community sanitation), with a low prevalence of MS correlated with a high prevalence of Trichuris infection [40].

\section{Management of MS in Latin America}

The advent of oral treatments for RRMS, such as fingolimod and teriflunomide, has expanded treatment options in Latin America. Availability of these disease-modifying therapies provides an opportunity for clinicians to improve management and optimize the treatment of patients with RRMS in clinical practice. Indeed, recent guidelines have detailed recommendations for treatment optimization specifically for Latin America [36]. For example, in accordance with local drug availability and regulatory requirements, fingolimod has been recommended as an option for treatment initiation and for patients with a suboptimal response [36].

In addition to clinical efficacy and safety information for particular disease-modifying therapies, in Latin America, there are also regional socioeconomic issues with respect to drug availability, access to healthcare, and awareness of MS. For instance, in the context of limited drug intellectual property protection in some countries, there is the potential for patients to obtain and switch from originator licensed drugs to non-proprietary generic copies [41]. The use of such generics can be associated with unpredictable safety and efficacy implications [42].

The potential difference in genetic susceptibility and disease course may also impact on responsiveness to therapeutic agents in Latin Americans. This is seen in other minority ethnic populations, with a reduced response to IFN $\beta$ - 1 a reported among African Americans, for example, when compared with the US white population [43].

Overall, it is therefore important that data relating to the efficacy and safety/tolerability of fingolimod in Latin America should be generated by studies drawing from the appropriate ethnic backgrounds. Given the combination of epidemiologic and socioeconomic factors unique to Latin America versus other regions, data from defined ethnic groups will help clinicians to refine the selection of the best possible treatment options for patients with RRMS.

\section{EXPERIENCE WITH FINGOLIMOD IN LATIN AMERICA}

Availability of fingolimod has increased across Latin America in recent years; it is now approved in 13 countries in the region. As a result, experience with fingolimod in Latin America is broadening, with a range of studies reporting efficacy and safety outcomes, some of which are summarized in Table 2. 


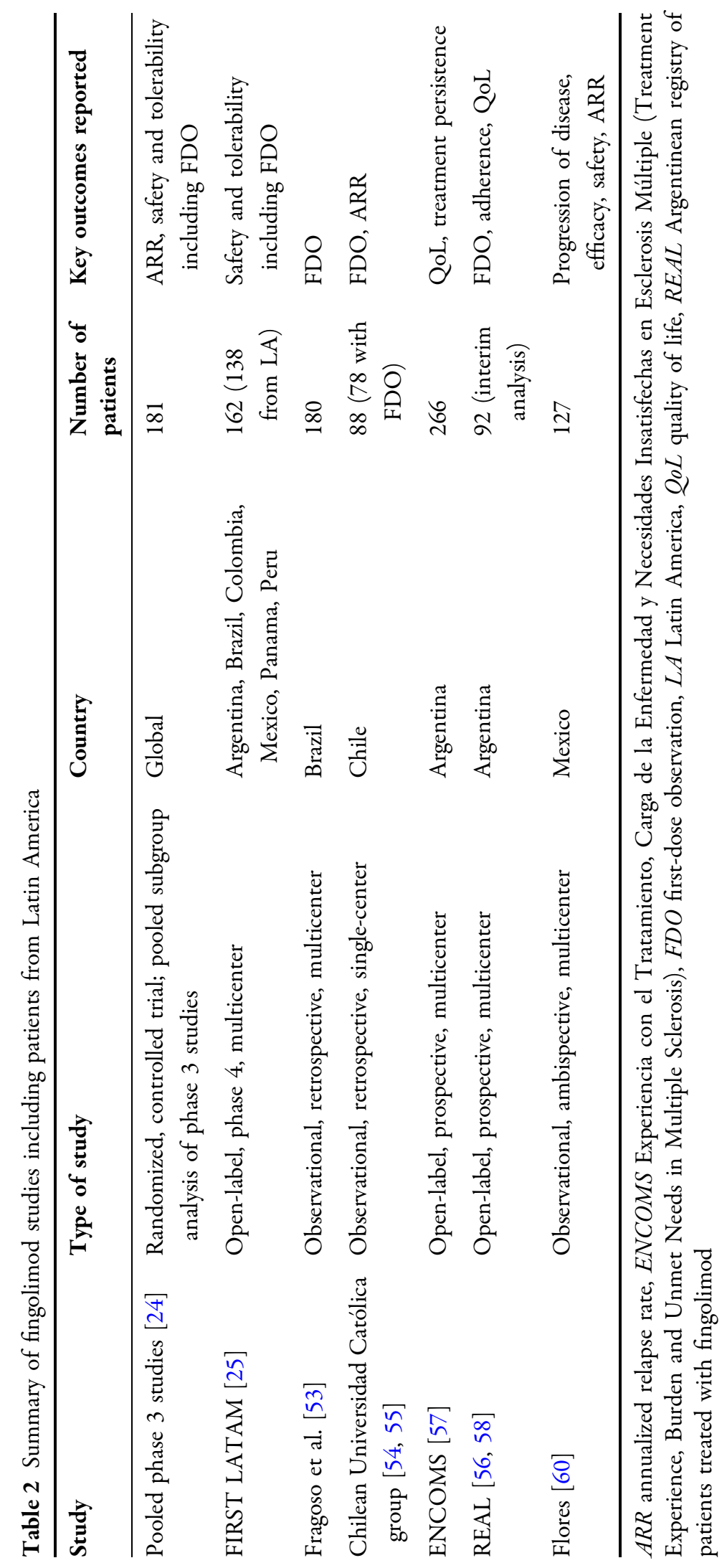




\section{Phase 3 Clinical Study Efficacy and Safety Data for Fingolimod in the Hispanic Population}

A post hoc analysis focused on the Hispanic cohort from the three pivotal, phase 3 studies of fingolimod (key results from which are summarized in Table 1) [3-5, 24]. Pooled efficacy and safety data from all randomized Hispanic patients $(n=181)$ gave the largest possible dataset, with the following treatment groups: fingolimod $0.5 \mathrm{mg}(n=89)$, IFN $\beta$-1a IM $(n=65)$, and placebo $(n=27)$. Over the analysis period, the ARRs in Hispanic patients were numerically lower in the fingolimod $0.5 \mathrm{mg}$ group, with relative numerical reductions of $52 \%$ versus placebo and $35 \%$ versus IFN $\beta-1$ a IM: ARRs of 0.22 [95\% confidence interval (CI) 0.14-0.35] for fingolimod, $0.46 \quad(95 \%$ CI $0.24-0.88)$ for placebo, and $0.34 \quad(95 \% \mathrm{CI}$ 0.18-0.63) for IFN $\beta-1$ a IM.

Importantly, relative reductions in ARR were of similar magnitude in the Hispanic cohort and in the overall population, indicating that fingolimod has efficacy in this ethnic group that is similar to that in the wider study population.

First-dose administration of fingolimod is associated with a transient decrease in heart rate (HR) and slowing of atrioventricular (AV) conduction, owing to well-understood and expected pharmacodynamic effects of fingolimod treatment initiation [44-46]. In the FREEDOMS (ClinicalTrials.gov number, NCT00289978), FREEDOMS II (ClinicalTrials.gov number, NCT00355134), and TRANSFORMS (ClinicalTrials.gov number, NCT00340834) studies, the first-dose effects of fingolimod on HR and rhythm typically resolved spontaneously within $24 \mathrm{~h}[3-5,45]$. Symptoms of conduction delays were reported in less than $1 \%$ of patients, and were typically mild or moderate in severity.
The post hoc analysis of the Hispanic cohort of the pooled population from these trials reported data on first-dose observations that were consistent with the overall population [24]. A transient decrease in HR was observed in some Hispanic patients, consistent with findings in the overall population. In both the overall population and in the Hispanic cohort, HR started to attenuate $6 \mathrm{~h}$ after initial fingolimod administration. No cases of symptomatic bradycardia were reported in the Hispanic patients. Newly occurring electrocardiographic (ECG) events were observed in $11.4 \%$ of the Hispanic patient population receiving fingolimod, compared with $9.4 \%$ of the IFN $\beta-1$ a IM group and $3.8 \%$ of the placebo group. These events included first-degree AV block (occurring in $4.5 \%$ of patients receiving fingolimod), which were typically asymptomatic. In previous studies, the rates of $\mathrm{AV}$ block in the overall population of patients receiving fingolimod have been in the range $0-5 \%[9-11,15]$, which is consistent with that observed in the Hispanic cohort. Importantly, the majority $(88.8 \%)$ of Hispanic patients in the fingolimod group were discharged at $6 \mathrm{~h}$ following the first dose.

The post hoc analysis of Hispanic patients also reported on general adverse event (AE) data. The overall incidence of AEs was similar across the fingolimod, placebo, and IFN $\beta-1$ a IM groups. Nasopharyngitis, headache, and urinary tract infection were among the most common AEs in all three treatment groups [24].

\section{Phase 4 Safety and Tolerability Findings from the Open-Label FIRST LATAM Study}

Whereas assessment of AEs in the phase 3 studies indicated that the safety profile of fingolimod in Hispanic patients was consistent with that reported in the overall patient 
population, the open-label FIRST LATAM (ClinicalTrials.gov number, NCT01497262) study was specifically designed to evaluate the safety and tolerability of fingolimod in an ethnically relevant MS patient population in Latin American countries [25, 47]. FIRST LATAM was a 16-week, multinational safety study enrolling patients across eight countries, including six from Latin America (Argentina, Brazil, Colombia, Mexico, Panama, Peru), and which had a study population including patients with controlled diabetes mellitus and certain cardiac and pulmonary conditions that were excluded from pivotal studies [25].

In the FIRST LATAM study, first-dose monitoring observations were systematically collected in line with the study protocol and, reassuringly, these were consistent with those described in previous fingolimod clinical studies [45]. Transient decreases in HR and blood pressure started to recover by $6 \mathrm{~h}$ following the first dose. Most (90.6\%) patients were asymptomatic during first-dose monitoring and were discharged at $6 \mathrm{~h}$ post-dose. Bradycardia and dizziness occurred in 3.6\% and $0.7 \%$ of patients, respectively. For all patients, these symptoms resolved on the same day without medical treatment and did not require extended monitoring. Of the 130 (94.2\%) patients who completed the study, $59.4 \%$ reported an $\mathrm{AE}$ and $5.1 \%$ reported a serious AE (SAE). Events of particular interest were bradyarrhythmias (8.7\%), infections (23.9\%), hypertension (2.2\%), and liver-related investigations (3.6\%).

\section{Real-World Experience of Fingolimod Across the Globe and in Latin America}

Results from clinical trials cannot be generalized to an entire disease population because of restrictions in trial design such as patient eligibility criteria and the type of patients willing to enter a study. Hence, postmarketing studies are important in providing information about the use of a drug in a realworld setting, which includes patient populations that are not eligible for entry into a clinical trial. Studies of real-life experience in different populations support the short safety and tolerability of fingolimod in clinical practice [48-50]. First-dose observation data from these studies are in line with the phase 3 trials data [48-50]. Fingolimod discontinuation owing to AEs was higher at 3 months in clinical practice $(8.2 \%)$ than observed in clinical trials (7.6\%) [49]. However, it should be noted that discontinuation owing to AEs was similar to expected AEs and headache was the most frequent cause of discontinuation (1.3\%) [49], reflecting the incidence of headache AEs in pivotal clinical trials (26.5\%) [51]. Overall, a low incidence of specific AEs and SAEs was observed in these real-world studies performed in different patient populations [48-50], which were consistent with the previously described safety profile of fingolimod in phase 3 clinical trials [3-5]. Furthermore, data collected from these real-world studies are of interest because some included patients who would have been excluded from fingolimod pivotal studies owing to systemic diseases, including diabetes mellitus, cardiac and pulmonary diseases. Fingolimod was well tolerated in patients with these comorbidities $[49,52]$. Nevertheless, the long-term safety in these patients is still unknown and needs further evaluation.

As real-world experience of fingolimod treatment in Latin Americans accumulates, it is becoming increasingly apparent that safety outcomes are similar to those in populations from the rest of the world. A summary of the key findings from real-world studies of MS in Latin America is given here. 
In a review of cardiovascular data from 180 patients with MS receiving a first dose of fingolimod in Brazil [53], a total of 12 (6.7\%) patients required extended monitoring beyond $6 \mathrm{~h}$ owing to symptomatic bradycardia, whereas in clinical trials symptomatic bradycardia was reported by $0.6 \%$ of patients. This difference may be due to less stringent exclusion criteria in the clinical trials compared with the real-world setting. Additionally, it should be noted that many of the patients with ECG abnormalities after fingolimod administration had existing cardiac abnormalities at baseline. Reassuringly, these patients did not develop complications after fingolimod administration. As a precautionary measure, three $(1.7 \%)$ patients were managed for right branch/second-degree $\mathrm{AV}$ block (although a precise description of these ECG abnormalities and outcomes was not provided). Overall, at the time of publication, 179 (99.4\%) patients in the study were continuing fingolimod treatment.

Real-world experience of fingolimod supports the clinical trial findings in Hispanic patients that the effect of first-dose administration on $\mathrm{HR}$ is typically asymptomatic [24]. In a retrospective, observational study of 78 patients in Chile, first-dose observations during the initial $6 \mathrm{~h}$ post-dose showed that no patient had symptomatic bradycardia or required hospitalization, with all patients meeting discharge criteria [54]. Furthermore, the same Chilean MS center reported that fingolimod treatment in 88 patients (of whom 66\% had failed previous therapy) significantly reduced ARR from 1.35 to $0.42(P<0.0001)$ [55]. In Argentina, an interim analysis of 92 patients from the 2-year, open-label, prospective REAL (Argentinean registry of patients treated with fingolimod) study, which aims to include 200 patients, showed an effect of fingolimod on
HR during treatment initiation which was similar to that reported in the FIRST LATAM and pivotal studies. Of the 92 patients, three (3.3\%) required ECG monitoring beyond $6 \mathrm{~h}$, although all were discharged after $9 \mathrm{~h}$ of observation; no patient had symptomatic bradycardia [56]. The Argentinian, open-label, prospective, multicenter ENCOMS [Experiencia con el Tratamiento, Carga de la Enfermedad y Necesidades Insatisfechas en Esclerosis Múltiple (Treatment Experience, Burden and Unmet Needs in Multiple Sclerosis)] study of 266 patients demonstrated that MS relapses can have a detrimental effect on patient quality of life (QoL) [57]; the REAL study showed benefits of fingolimod treatment on QoL outcomes and treatment persistence [58]. In Puerto Rico, a single-center study of 50 patients suggested that, in the Hispanic population, fingolimod can reduce the development of MRI T1 hypointense lesions (black holes) and brain atrophy after 1 year [59]. In Mexico, an observational, ambispective, multicenter study of 127 patients showed that fingolimod had a greater beneficial effect on MS progression at earlier compared with later stages of disease and also in younger compared with older patients [60].

\section{DISCUSSION: INTERPRETATION AND IMPLICATIONS}

Overall, this review indicates that the efficacy and safety data for fingolimod derived from clinical and real-world evaluations of Hispanic and Latin American patients are very similar to those reported for the overall study populations and patients from other countries, including observations during first-dose monitoring [3-5, 52]. These findings provide reassurance for clinicians and patients alike. However, studies 
of efficacy in Latin American patients thus far have generally been limited to the evaluation of relapse rate outcomes. In the clinical trial program, fingolimod further demonstrated a consistent significant reduction in inflammatory disease activity and BVL, as measured by MRI, and significant effects on several measures of disability in the overall study populations [3-5]. Additional research would ideally investigate these treatment responses specifically in patients with MS from Latin America [36].

It is also important to acknowledge particular health issues endemic in Latin America, such as the high prevalence of tuberculosis, influenza, herpes zoster, and human T-lymphotropic virus infection [61]. This is an important consideration because, while the overall incidence of infections was similar between fingolimod and control groups in the phase 3 studies, pooled analyses showed a slightly higher incidence of infections such as herpes zoster in patients treated with fingolimod $(1.5 \%)$ than in those receiving placebo (0.8\%) [51]. This trend appears consistent with findings in Latin American patients. As patient exposure to fingolimod increases in the region, ongoing vigilance for opportunistic infections is certainly warranted but, so far, no new safety signals have emerged. A recent, randomized, placebo-controlled study in patients with MS looked at immune response to influenza and tetanus vaccines; the results indicated that while patients receiving fingolimod were able to mount immune responses, their response rates to the vaccines were reduced when compared with those receiving placebo [62]. Thus, label recommendations and existing risk management plans should be carefully adhered to [1]. Current label recommendations state that, as with any immune-modulating
Table 3 Availability of therapy options for multiple sclerosis in 20 Latin American countries in 2011 [63]

\begin{tabular}{|c|c|}
\hline Availability & $n(\%)$ \\
\hline \multicolumn{2}{|l|}{ Acute crisis } \\
\hline Methylprednisolone & $20(100)$ \\
\hline Intravenous gamma globulin & $20(100)$ \\
\hline Plasmapheresis & $18(90)$ \\
\hline \multicolumn{2}{|l|}{ Immunomodulators } \\
\hline Interferons & $20(100)$ \\
\hline Glatiramer acetate & $7(35)$ \\
\hline Biosimilars & $7(35)$ \\
\hline Natalizumab & $11(55)$ \\
\hline Fingolimod & $4(20)$ \\
\hline \multicolumn{2}{|l|}{ Immunosuppressive drugs } \\
\hline Azathioprine & $20(100)$ \\
\hline Cyclophosphamide & $20(100)$ \\
\hline Mitoxantrone & $18(90)$ \\
\hline \multicolumn{2}{|c|}{ Participation in associations/studies/guides } \\
\hline Patient-family associations & $20(100)$ \\
\hline MS centers/clinics & $12(60)$ \\
\hline National clinical studies & $11(55)$ \\
\hline International clinical studies & $12(60)$ \\
\hline MS academic associations & $10(50)$ \\
\hline Clinical trials & $10(50)$ \\
\hline Treatment guides & $10(50)$ \\
\hline Therapeutic effectiveness trials & $2(10)$ \\
\hline
\end{tabular}

North America Mexico, Cuba, Puerto Rico, Dominican Republic; Central America Costa Rica, El Salvador, Guatemala, Honduras, Nicaragua, Panama; South America Argentina, Bolivia, Brazil, Colombia, Chile, Ecuador, Paraguay, Peru, Uruguay, Venezuela $M S$ multiple sclerosis

drug, patients should be monitored for signs and symptoms of infection during fingolimod treatment and for 2 months after discontinuation, and treatment should not be initiated in patients with active acute or chronic 
infections [1]. With regard to herpes zoster infection, patients without a history of chickenpox or without vaccination against varicella zoster virus (VZV) should be tested for antibodies to $\mathrm{VZV}$, and vaccination of antibody-negative patients should be considered prior to commencing treatment [1]. Aside from efficacy and safety considerations, it is also worth considering that algorithms for the management of MS in Europe/North America may not reflect practical issues relating to healthcare provision in Latin America [61]. While fingolimod is now approved in 13 Latin American countries, some data suggest that it is not yet fully available. For example, an unofficial survey conducted at meetings in Colombia and Ecuador in 2011 found that fingolimod was available in only four of the 20 countries included in the analysis, compared with all 20 countries having access to IFN $\beta$ (Table 3) [63]. However, it is reasonable to assume that there have been improvements in fingolimod availability in Latin America since 2011, with further improvements expected over the next few years. As fingolimod becomes more widely available and easier to prescribe, the increased experience of this compound across Latin America will become ever more relevant and allow better assessment of the fingolimod risk:benefit ratio in this ethnic group.

\section{CONCLUSIONS}

Expanding clinical and real-world experience of fingolimod in patients from Latin America indicates that efficacy and safety outcomes are similar to those of patients from the rest of the world. It is important to consider the particular features of MS in Latin America, as well as socioeconomic factors, when tailoring treatment optimization strategies for patients across the region, and further research is required in this ethnic group. However, overall, current data show that fingolimod should be considered a good option for treating Latin American patients with MS early in the course of the disease.

\section{ACKNOWLEDGMENTS}

All named authors meet the International Committee of Medical Journal Editors (ICMJE) criteria for authorship of this manuscript, take responsibility for the integrity of the work as a whole, and have given final approval to the version to be published. Dr. Jorge Correale acts as the guarantor for this paper. This review, the article processing charges, and the open access fee were funded by Novartis Pharma AG, Basel, Switzerland. Editorial support in the preparation of this manuscript was provided by Stephen Georgiou, Ph.D., and Sarah Griffiths, PhD, of Oxford PharmaGenesis Ltd, Oxford, UK, and was funded by Novartis Pharma AG.

Conflict of interest. Jorge Correale has served as an advisory board member for Genzyme, Merck Serono Argentina, Merck Serono LATAM, and Novartis Argentina. $\mathrm{He}$ has received reimbursement for developing educational presentations for Biogen Idec Argentina, Genzyme Argentina, Merck Serono Argentina, Novartis Argentina, Novartis LATAM, and Teva Tuteur Argentina, as well as professional travel and accommodation stipends. Jose Flores has served as an advisory board member for Bayer, Biogen Idec, Genzyme Mexico, Merck Serono Mexico, Merck Serono LATAM, and Novartis Mexico. He has received reimbursement for developing educational presentations for Biogen Idec LATAM, Merck Serono Mexico, and Novartis Mexico, as well as professional travel and 
accommodation stipends. Juan Garcia Bonitto has served as an advisory board member for Novartis Columbia and Genzyme. He has received speaking honoraria from Genzyme, Merck Serono, Novartis, and Teva. Claudia Cárcamo Rodríguez has served as an advisory board member for Genzyme, Merck Serono LATAM, and Novartis Chile. She has received reimbursement for developing educational presentations for Bayer, Merck Serono LATAM, and Novartis Chile, as well as professional travel and accommodation stipends. Enedina M. L. Oliveira has received speaking/consulting honoraria from Bayer, Biogen Idec, Genzyme, Merck Serono, Novartis, and Teva, and has had travel expenses to scientific meetings sponsored by Bayer, Merck Serono, and Teva.

Compliance with ethics guidelines. The analyses in this article are based on previously conducted studies, and do not involve any new studies of human or animal subjects performed by any of the authors.

Open Access. This article is distributed under the terms of the Creative Commons Attribution Noncommercial License which permits any noncommercial use, distribution, and reproduction in any medium, provided the original author(s) and the source are credited.

\section{REFERENCES}

1. US Food and Drug Administration. Gilenya ${ }^{\circledR}$ (fingolimod) prescribing information; 2014. http:// www.accessdata.fda.gov/drugsatfda_docs/label/2014/ 022527s009lbl.pdf. Accessed June 16, 2014.

2. Novartis Pharma AG. Data on file. 2015.

3. Calabresi PA, Radue EW, Goodin D, et al. Safety and efficacy of fingolimod in patients with relapsingremitting multiple sclerosis (FREEDOMS II): a double-blind, randomised, placebo-controlled, phase 3 trial. Lancet Neurol. 2014;13:545-56.
4. Cohen JA, Barkhof F, Comi G, et al. Oral fingolimod or intramuscular interferon for relapsing multiple sclerosis. N Engl J Med. 2010;362:402-15.

5. Kappos L, Radue EW, O'Connor P, et al. A placebocontrolled trial of oral fingolimod in relapsing multiple sclerosis. N Engl J Med. 2010;362:387-401.

6. Kappos L, Radue EW, O'Connor P, et al. Phase III FREEDOMS study extension: fingolimod (FTY720) efficacy in patients with relapsing-remitting multiple sclerosis receiving continuous or placebofingolimod switched therapy for up to 4 years. Mult Scler J. 2012;18:451-2.

7. Montalban X, Barkhof F, Comi G, et al. Long-term comparison of fingolimod with interferon-beta-1a: results of 4.5-year follow-up from the extension phase III TRANSFORMS study. Mult Scler J. 2012;18:219.

8. Reder AT, Jeffery D, Goodin D, et al. Long-term efficacy of fingolimod in patients with relapsing remitting multiple sclerosis: results from the phase 3 FREEDOMS II extension study. Mult Scler J. 2013;19:510-1.

9. Kappos L, Cohen JA, Barkhof F, et al. Relapse rates and disability remain consistently low with longterm fingolimod therapy: five-year interim results of the LONGTERMS extension study. Mult Scler J. 2013;19:486-7.

10. Rosenstiel PV, Cohen J, Gottschalk R, et al. Longterm safety of fingolimod: interim evaluation of data from the LONGTERMS trial. J Neurol. 2014;261:S248.

11. Kappos L, Radue E, Freedman M. Inclusion of brain volume loss in a revised measure of multiple sclerosis disease-activity freedom: the effect of fingolimod. Mult Scler J. 2014;20:Abstract 1570.

12. Montalban X, Cohen J, Barkof F, et al. Effect of fingolimod versus interferon-beta $1 \mathrm{a}$ on no evidence of disease activity or worsening (NEDA-4) in the TRANSFORMS study. Neurology. 2015;84(P4):001.

13. Bergvall N, Makin C, Lahoz R, et al. Relapse rates in patients with multiple sclerosis switching from interferon to fingolimod or glatiramer acetate: a US claims database study. PLoS ONE. 2014;9:e88472.

14. He A, Spelman T, Jokubaitis V, et al. Comparison of switch to fingolimod or interferon beta/glatiramer acetate in active multiple sclerosis. JAMA Neurol. 2015;72:405-13.

15. Duerr HP, Alsop J, Bergvall N, et al. Effectiveness of fingolimod compared with interferons and glatiramer acetate for the treatment of multiple 
sclerosis: a matched comparison of treatments from the PANGAEA and PEARL studies. Neurology. 2015;84(14 Suppl):P3.253.

16. Bergvall N, Petrilla AA, Karkare SU, et al. Persistence with and adherence to fingolimod compared with other disease-modifying therapies for the treatment of multiple sclerosis: a retrospective US claims database analysis. J Med Econ. 2014;17:696-707.

17. Lapierre Y, Selchen D, Devonshire V, et al. Switching from injectable therapy leads to high continuation rate on fingolimod. Neurology. 2014;82(10 Suppl):P7.221.

18. Comi G, Gold R, Dahlke F, et al. Relapses in patients treated with fingolimod after previous exposure to natalizumab. Mult Scler J. 2014. doi:10.1177/ 1352458514549404.

19. Kappos L, Radue E-W, Comi G, et al. Switching from natalizumab to fingolimod: a randomized, placebocontrolled study of patients with RRMS. Neurology. 2015. doi:10.1212/WNL.0000000000001706.

20. Correale J. MS in Latin America. Int MS J. 2008;15:3-5.

21. Claudio-Campos K, Duconge J, Cadilla CL, et al. Pharmacogenetics of drug-metabolizing enzymes in US Hispanics. Drug Metabol Drug Interact. 2014. doi:10.1515/dmdi-2014-0023/j/dmdi.ahead-of-print/ dmdi-2014-0023/dmdi-2014-0023.xml.

22. Suarez-Kurtz G. Pharmacogenomics in admixed populations: the Brazilian pharmacogenetics/ pharmacogenomics network-REFARGEN. Pharmacogenomics J. 2004;4:347-8.

23. O'Gorman C, Lucas R, Taylor B. Environmental risk factors for multiple sclerosis: a review with a focus on molecular mechanisms. Int $\mathrm{J}$ Mol Sci. 2012;13:11718-52.

24. Chinea Martinez AR, Correale J, Coyle PK, et al. Efficacy and safety of fingolimod in Hispanic patients with multiple sclerosis: pooled clinical trial analyses. Adv Ther. 2014;31:1072-81.

25. Ordoñez Boschetti L, Rey R, Cruz A, et al. Safety and tolerability of fingolimod in Latin American patients with relapsing-remitting multiple sclerosis: the Open Label FIRST LATAM study. Adv Ther. 2015. doi:10.1007/s12325-015-0224-2.

26. Multiple Sclerosis International Federation. Atlas of MS; 2013. http://www.msif.org/about-us/advocacy/ atlas-of-ms/. Accessed January 12, 2015.

27. Cristiano E, Rojas J, Romano $M$, et al. The epidemiology of multiple sclerosis in Latin
America and the Caribbean: a systematic review. Mult Scler J. 2013;19:844-54.

28. Cordova J, Vargas S, Sotelo J. Western and Asian features of multiple sclerosis in Mexican Mestizos. Clin Neurol Neurosurg. 2007;109:146-51.

29. Rojas JI, Patrucco L, Cristiano E. Multiple sclerosis in Argentina. Systematic review and meta-analysis. Medicina (B Aires). 2012;72:449-54.

30. Bostrom I, Stawiarz L, Landtblom AM. Sex ratio of multiple sclerosis in the National Swedish MS Register (SMSreg). Mult Scler. 2013;19:46-52.

31. Orton SM, Herrera BM, Yee IM, et al. Sex ratio of multiple sclerosis in Canada: a longitudinal study. Lancet Neurol. 2006;5:932-6.

32. Cardoso E, Fukuda T, Pereira J, et al. Clinical and epidemiological profile of multiple sclerosis in a reference center in the State of Bahia, Brazil. Arq Neuropsiquiatr. 2006;64:727-30.

33. Abad P, Perez M, Castro E, et al. Prevalence of multiple sclerosis in Ecuador. Neurologia. 2010;25:309-13.

34. Melcon MO, Melcon CM, Bartoloni L, et al. Towards establishing MS prevalence in Latin America and the Caribbean. Mult Scler. 2013;19:145-52.

35. Leray E, Morrissey S, Yaouanq J, et al. Long-term survival of patients with multiple sclerosis in West France. Mult Scler. 2007;13:865-74.

36. Correale J, Abad P, Alvarenga R, et al. Management of relapsing-remitting multiple sclerosis in Latin America: practical recommendations for treatment optimization. J Neurol Sci. 2014;339:196-206.

37. Dalmay F, Bhalla D, Nicoletti A, et al. Multiple sclerosis and solar exposure before the age of 15 years: case-control study in Cuba, Martinique and Sicily. Mult Scler. 2010;16:899-908.

38. Rito Y, Flores J, Fernandez Aguilar A, et al. Vitamin $D$ in multiple sclerosis patients: not the same risk for everybody. Mult Scler J. 2015. doi:10.1177/ 1352458515576986.

39. Correale J, Farez M. Association between parasite infection and immune responses in multiple sclerosis. Ann Neurol. 2007;61:97-108.

40. Fleming JO, Cook TD. Multiple sclerosis and the hygiene hypothesis. Neurology. 2006;67:2085-6.

41. Kaplan WA, Wirtz VJ, Stephens P. The market dynamics of generic medicines in the private sector of 19 low and middle income countries between 2001 and 2011: a descriptive time series analysis. PLoS ONE. 2013;8:e74399. 
42. Correale J, Chiquete E, Milojevic S, et al. Assessing the potential impact of non-proprietary drug copies on quality of medicine and treatment in patients with relapsing multiple sclerosis: the experience with fingolimod. Drug Des Devel Ther. 2014;8:859-67.

43. Cree BA, Al-Sabbagh A, Bennett R, et al. Response to interferon beta-1a treatment in African American multiple sclerosis patients. Arch Neurol. 2005;62:1681-3.

44. Vanoli E, Pentimalli F, Botto G. Vagomimetic effects of fingolimod: physiology and clinical implications. CNS Neurosci Ther. 2014;20:496-502.

45. DiMarco JP, O'Connor P, Cohen JA, et al. First-dose effects of fingolimod: pooled safety data from three phase 3 studies. Mult Scler Relat Disord. 2014;3:629-38.

46. Koyrakh L, Roman MI, Brinkmann V, et al. The heart rate decrease caused by acute FTY720 administration is mediated by the $\mathrm{G}$ protein-gated potassium channel I. Am J Transplant. 2005;5:529-36.

47. Alvarenga R, Rey R, Cruz A, et al. Safety and tolerability of fingolimod $0.5 \mathrm{mg}$ in relapsingremitting MS patients in the FIRST LATAM study. Poster presented at 8th Latin American Congress of Multiple Sclerosis (LACTRIMS) Meeting, 26-29 Nov 2014, Lima.

48. Al-Hashel J, Ahmed SF, Behbehani R, et al. Realworld use of fingolimod in patients with relapsing remitting multiple sclerosis: a retrospective study using the national multiple sclerosis registry in Kuwait. CNS Drugs. 2014;28:817-24.

49. Ontaneda D, Hara-Cleaver C, Rudick RA, et al. Early tolerability and safety of fingolimod in clinical practice. J Neurol Sci. 2012;323:167-72.

50. Ramseier SP, Roth S, Czaplinski A. A Swiss real world best practice experience in three different clinical settings of the 6 hour fingolimod first dose observation procedure. BMC Pharmacol Toxicology. 2015;16:7.

51. Kappos L, Cohen J, Collins W, et al. Fingolimod in relapsing multiple sclerosis: an integrated analysis of safety findings. Mult Scler Relat Disord. 2014;3:494-504.

52. Gold R, Comi G, Palace J, et al. Assessment of cardiac safety during fingolimod treatment initiation in a real-world relapsing multiple sclerosis population: a phase $3 \mathrm{~b}$, open-label study. J Neurol. 2014;261:267-76.

53. Fragoso YD, Arruda CC, Arruda WO, et al. The reallife experience with cardiovascular complications in the first dose of fingolimod for multiple sclerosis. Arq Neuropsiquiatr. 2014;72:712-4.

54. Vergara Soto E, Uribe San Martín R, Ciampi Díaz E, et al. Safety in first dose of Fingolimod administered in an ambulatory way in patients controlled at Centro de Esclerosis Múltiple de la Pontificia Universidad Católica de Chile. Abstract presented at 8th Latin American Congress of Multiple Sclerosis (LACTRIMS) Meeting, 26-29 Nov 2014, Lima.

55. Uribe San Martín R, Ciampi Díaz E, Vásquez Torres $M$, et al. Effectivity and safety of fingolimod and natalizumab treatments in patients controlled at Centro de Esclerosis Múltiple de la Pontificia Universidad Católica de Chile. Abstract presented at 8th Latin American Congress of Multiple Sclerosis (LACTRIMS) Meeting, 26-29 Nov 2014, Lima.

56. Kuperman GA, Nunez V, Mattiazi M, et al. Cardiac safety profile during first-dose monitoring period of fingolimod (Gilenya) treatment in patients with relapsing remitting MS: data from the Argentinean registry (REAL). Interim results. Neurology. 2015;84(14 Suppl):P3.250.

57. Ysrraelit C, Caceres F, Villa A, et al. Impact of relapses on patient reported outcomes in patients with multiple sclerosis in Argentina: data based on a population from a multicenter study. Abstract presented at 8th Latin American Congress of Multiple Sclerosis (LACTRIMS) Meeting, 26-29 Nov 2014, Lima, 2014:P6.00.

58. Kuperman GA, Villa AM, Caceres F, et al. Interim analysis II from REAL Study: Quality of life and persistence with fingolimod treatment in relapsing remitting multiple sclerosis patients in Argentina. Neurology. 2015;84(14 Suppl):P3.255.

59. Chinea AR, Hernandez YG, Estades ER. Can fingolimod reduce the occurrence of MRI proven black hole and cerebral atrophy burden in Hispanic population with multiple sclerosis? Mult Scler. 2014;20(1 Suppl):P320.

60. Flores. Fingolimod experience in 127 Mexican patients; 2015 (manuscript in prep.).

61. Finkelsztejn A, Gabbai AA, Fragoso YD, et al. Latin American algorithm for treatment of relapsingremitting multiple sclerosis using diseasemodifying agents. Arq Neuropsiquiatr. 2012;70:799-806.

62. Kappos L, Mehling M, Arroyo R, et al. Randomized trial of vaccination in fingolimod-treated patients with multiple sclerosis. Neurology. 2015;84:872-9.

63. Gracia F, Armien B. Therapeutic armamentarium and health system coverage of multiple sclerosis in Latin America. Neuroepidemiology. 2012;38:217-8. 